\title{
INDONESIAN THROUGHFLOW
}

\section{TRANSPORT VARIABILITY ESTIMATED}

\section{FROM Satellite

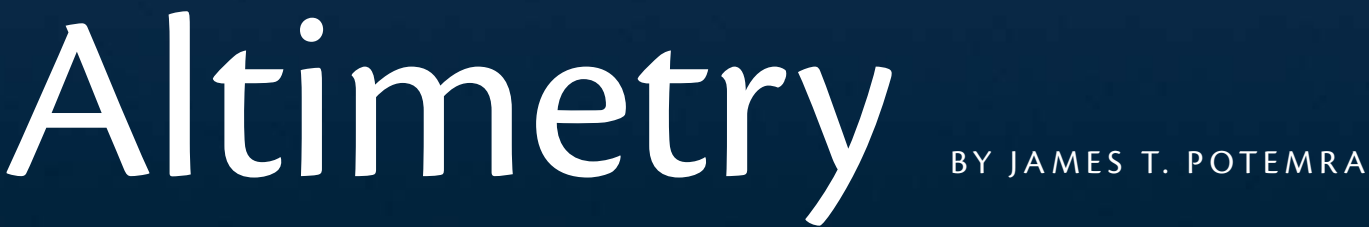

Figure 1. The Pacific to Indian Ocean exchange, known as the Indonesian throughflow (ITF), has been sampled with a repeat expendable bathythermograph (XBT) hydrographic section from Australia to Indonesia (IX-1, red stars). Sea-level estimates from the TOPEX/Poseidon (T/P) satellite (ground tracks given with the black lines) are used to estimate ITF transport. The major straits through which the ITF passes are indicated on the map.

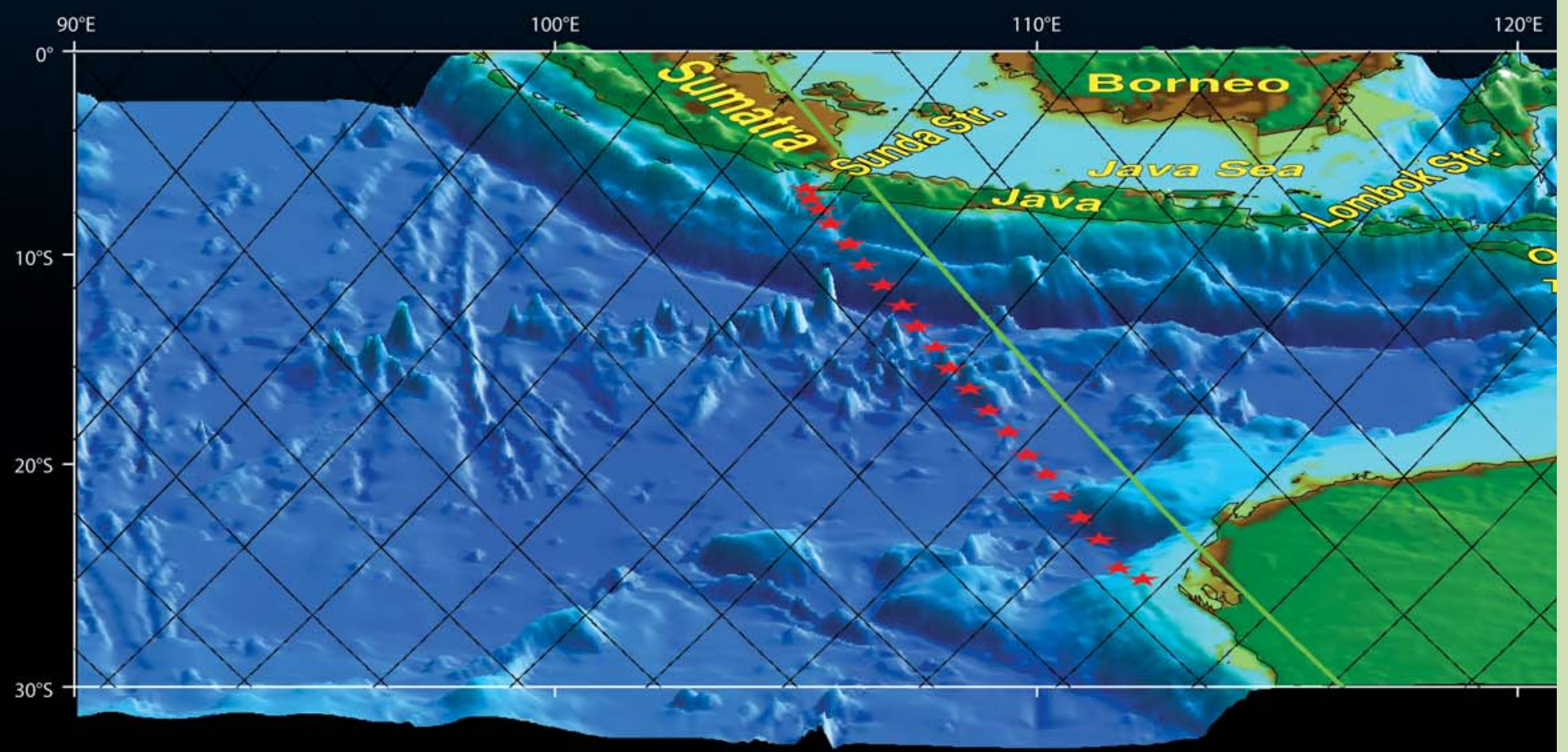


Potemra et al. (1997) (P97 model) showed that sea level in certain key regions, as measured by T/P, could be combined to produce an estimate of net ITF transport. A simple, linear model was constructed as follows:

$\mathrm{V}_{\text {ITF }}^{\mathrm{T}}(\mathrm{t})=\Sigma \alpha_{\mathrm{i}} \eta_{\mathrm{i}}(\mathrm{t})$,

where $\mathrm{V}_{\text {ITF }}^{\mathrm{T}}(\mathrm{t})$ is the total ITF volume transport as a function of time (mean removed), $\eta_{i}(t)$ are sea-level variations at location $i$ (mean removed and normalized to unit variance), and $\alpha_{\mathrm{i}}$ are weights determined from a least squares fit.

Since that study, advancements in numerical models and new in situ measurements have lead to a better understanding of the temporal and spatial variability of ITF transport, particularly the vertical variability of this flow (Potemra et al., 2003). In addition, there are now more than ten years of T/P measurements that can be used to make a more robust ITF index. For this study, version 1.0 NASA/ GSFC Ocean Pathfinder gridded sea-level variations (obtained from ftp://iliad.gsfc. nasa.gov) were used.

The P97 study is, therefore, revisited, using both a longer satellite record of sea level and a more sophisticated ocean model to determine the best fit (the $\alpha_{i}^{\prime}$ s in equation 1). As in P97, the relationship between ITF and sea level was determined using an ocean general circulation model (OGCM), and then this relationship was applied to the T/P

James T. Potemra (jimp@hawaii.edu) is Assistant Researcher, School of Ocean and Earth Science and Technology, International Pacific Research Center, University of $\mathrm{Ha}$ waii, Honolulu, HI, USA. altimeter data to estimate ITF transport. First, the variability of the ITF transport is described in order to judiciously select sea-level locations that will best reflect ITF forcing. Next, the model results are described, and finally the index is applied to the satellite data.

\section{ESTIMATES OF ITF}

TRANSPORT BASED ON OBSERVATIONS AND MODELS

Long-term, net ITF transport has been estimated from in situ observations in some of the key Indonesian passages. Understanding that these measurements have been acquired in different years, the mean ITF is estimated to be between 6.0 and 10.0 Sv (Hautala et al., 2001); see Gordon (this issue) for a full review.

Model estimates of ITF transport are typically higher than the observed estimates. Perhaps due to insufficient resolution of the complex bathymetry, or uncertainties in wind forcing, most large-scale models, particularly coarse resolution models, give net ITF transports in excess of $15 \mathrm{~Sv}$.

The model used in this study, the Simple Ocean Data Assimilation-Parallel Ocean Program (SODA POP 1.2) model (henceforth referred to as SODA) produces a realistic ITF transport with a net mean of $12.7 \mathrm{~Sv}$. This model has 40 vertical levels that vary from $10 \mathrm{~m}$ near the surface to 250-m thick in the deep ocean. The original SODA grid uses a "displaced pole," and is $0.4^{\circ}$ in longitude by $0.28^{\circ}$ latitude, but the model results were regridded to a regular $0.5^{\circ}$ by $0.5^{\circ}$ grid. The model was forced by ERA-40 daily averaged winds from the European Center for Medium Range Weather Forecasts (ECMWF). The model also uses a multivariate sequential data assimilation scheme (Carton et al., 2000) that updates the ocean model with observations of temperature and salinity every ten days. It should be noted that satellite altimeter data were not assimilated into the model run used in this study.

The annual cycle of ITF transport from SODA accurately shows peak transport during the southeast monsoon (roughly July-October) and minimum during the northwest monsoon, as predicted by Wyrtki (1961). The annual cycle is most evident in the upper 200 $\mathrm{m}$ in the SODA results (similar to other models), and represents about 60 percent of the variance in this layer $\left(9 \mathrm{~Sv}^{2}\right.$ compared to $15 \mathrm{~Sv}^{2}$ ). A deeper layer, 200 to $500 \mathrm{~m}$, has less overall variance $(6.9$ $\left.S v^{2}\right)$, but only 6 percent is due to seasonal variability.

This model result is consistent with the hypothesis that lower-frequency forcing of the ITF, for example, that associated with El Niño-Southern Oscillation (ENSO) variations, is evident in a deeper layer of the ITF (Potemra et al., 2003). Interannual variability in ITF transport is less well known than the seasonal cycle, mainly due to a lack of sufficiently long observations. One notable exception is the nearly twenty-year repeat expendable bathythermograph (XBT) section from Shark Bay, Australia to the Sunda Strait known as IX-1 (red stars in Figure 1). Meyers et al. (1995) computed upperocean transport ( 0 to approximately 400 m) based on these XBT data for the early part of the record and found a response to ENSO in the sense that warm El Niño events were associated with reduced ITF transport (Meyers, 1996). A possible explanation is that during these warm 
events, sea level in the western Pacific is anomalously low, thus reducing the $\mathrm{Pa}$ cific-to-Indian Ocean pressure gradient that is thought to drive the ITF. These results have been confirmed to a certain degree by recent modeling studies (e.g., England and Huang [2005] and McClean et al. [submitted]) in that time-filtered model transport values show a correlation to ENSO indices. The correlation, while significant, is not very high $(-0.37$ between upper ocean ITF transport and ENSO) (England and Huang, 2005), and depends on the vertical and horizontal section limits of the transport calculation. For example, transport near the coast of Australia shows a higher correlation with ENSO than transport variations near South Java (McClean et al., submitted).

The ITF-to-ENSO relationship is somewhat obscured when looking at total depth integrated transport because local winds act on the near-surface layer, while Pacific (ENSO) forcing controls ITF variations at a deeper depth. Further, ITF transport computed as the integral of velocity along the IX-1 section from Australia to Indonesia not only includes ITF influences, but also influences from Indian Ocean circulation (from the southern subtropical gyre) and from the South Java Current, a seasonal current along the southern coasts of Sumatra/Java. Indian Ocean forcing, such as from the Indian Ocean Dipole (IOD) (Saji et al., 1999), also complicates this signal, and directly influences transport on the northern edge of the Java/Australia section, while Pacific forcing controls low-frequency variations on the southern edge (Wijffels and Meyers, 2004). The time lag for Pacific-generated signals to reach the south- ern end of the Java/Australia section (England and Huang, 2005; McClean et al., submitted) is longer than those generated in the Indian Ocean, and thus there is not a coherent ENSO signal in the net, along-track integrated transport.

\section{SODA ITF Transport}

ITF transport was computed as the depth and cross-strait integral of zonal velocity from SODA along a line from Australia to South Java (Figure 2). This section is close to the IX-1 line of Meyers et al. (1995). The model velocity along this section is highest in the near-surface layer, particularly near the coast of Java.

Zonal velocity through this section is maximum between $11^{\circ} \mathrm{S}$ and the coast and reaches almost $50 \mathrm{~cm} \mathrm{~s}^{-1}$ in the upper $30 \mathrm{~m}$. It is half that value at $100 \mathrm{~m}$, and by $200 \mathrm{~m}$ the velocity is $12 \mathrm{~cm} \mathrm{~s}^{-1}$. South of $11^{\circ} \mathrm{S}$ the surface flow is between 0 and $10 \mathrm{~cm} \mathrm{~s}^{-1}$ (westward).

These velocities integrate to a net ITF transport of $12.7 \mathrm{~Sv}$. The variability of this transport is different in distinct re-
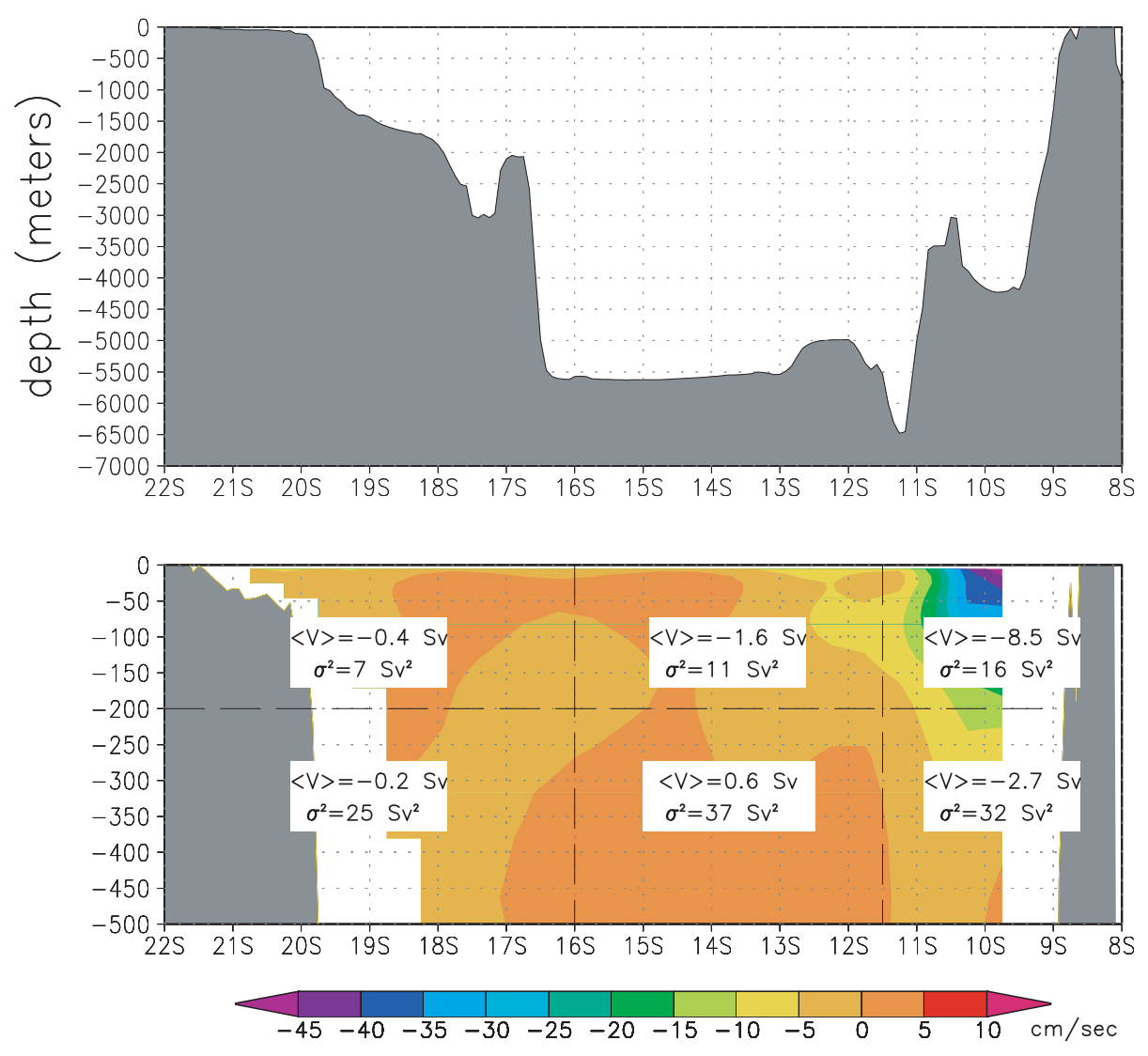

Figure 2. Data from transect shown in Figure 1 (green line). ITF transport occurs in discrete sections, both in the vertical and horizontal. The upper panel shows the bathymetry along a section from Australia (left side) to Java (right side). In the lower panel, the mean $(\langle V\rangle)$ and variance $\left(\sigma^{2}\right)$ of transport through two vertical and three horizontal subsections (indicated by the dashed lines) from the SODA model are given. Most of the transport in this model occurs near the surface off the coast of Java, but significant variability is seen at depth in all three subsections. 
gions along the track. The upper $200 \mathrm{~m}$ (upper 14 model levels) carry 83 percent of the total transport (10.6 Sv), and 80 percent of this occurs in the northern part of the section near the coast of Java. It is hypothesized that Indian Ocean effects, both direct wind forcing and coastal waves (e.g., Sprintall et al., 2000; Wijffels and Meyers, 2004) are seen near the coast of Java, while other forcing, including remote Pacific winds and local (Australian) alongshore winds are responsible for the variability in the southern part of the section. Thus, transport in these two ends of the Java/Australia section appear independent and in fact are uncorrelated in the SODA results.

The variance in transport is greatest in the lower layer of each of the Java/ Australia subsections (Figure 2), but the variance in total transport along the section is largest in the surface layer, $15 \mathrm{~Sv}^{2}$ compared to $7 \mathrm{~Sv}^{2}$ for the lower layer, suggesting that there is recirculation in the lower layer (i.e., the variance in each horizontal subsection cancels each other). Most of the variability in transport is at the annual and semi-annual periods (Figure 3), but interannual variations are strongest in the southern end of the section near Australia. This result is consistent with Pacific forcing driving the interannual variations, because these signals would follow a wave guide along the coasts of New Guinea and Australia (Wijffels and Meyers, 2004).

In summary, flow between Australia and south Java is influenced by local, seasonal winds that mostly affect the upper ocean flow, and low-frequency forcing from the Indian and Pacific Oceans that is seen at thermocline depth. A closer look at ITF transport from the SODA results shows that most of the ITF transport, computed along a line from Austra-
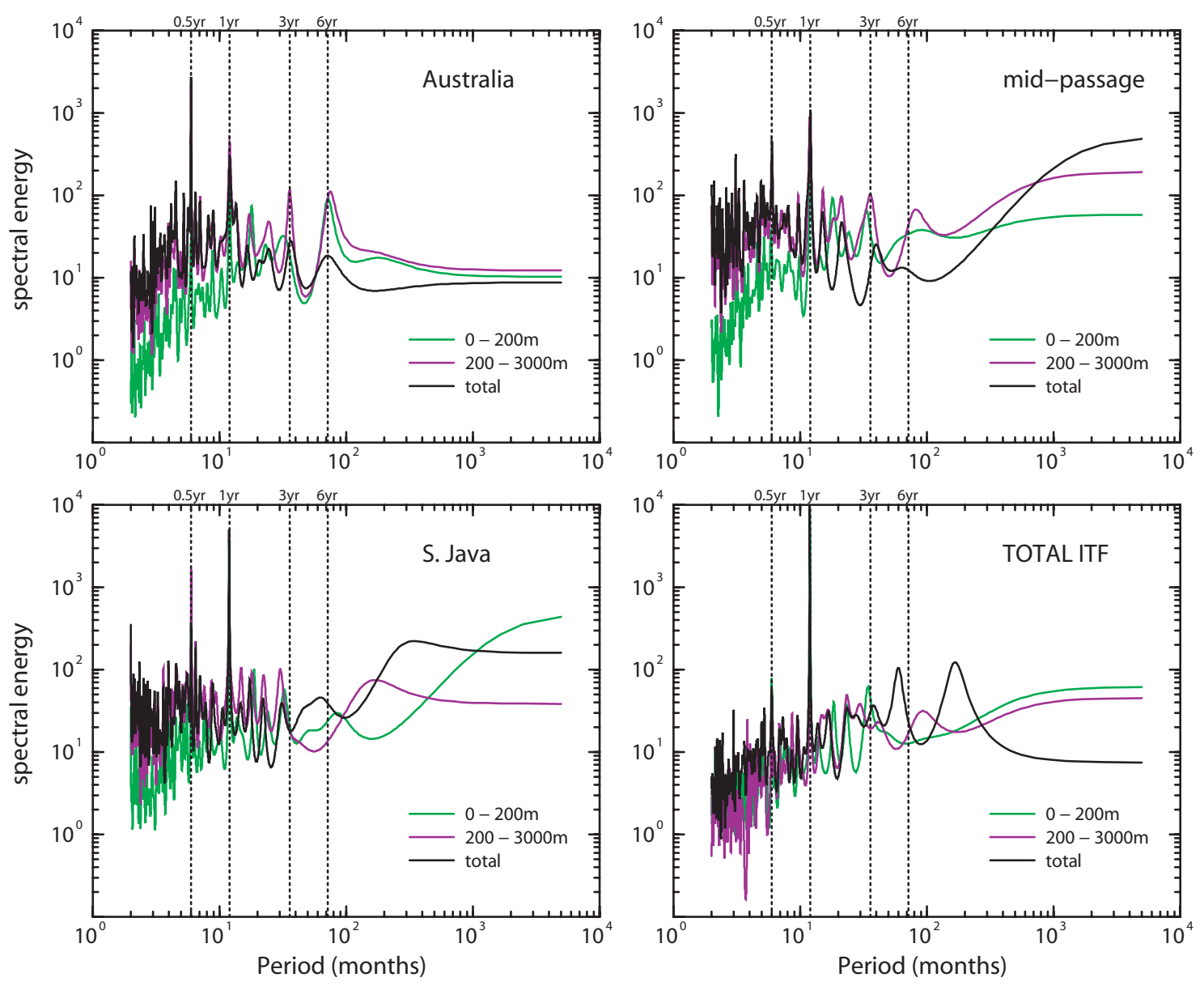

Figure 3 . The variability of transport from the subsections in Figure 2 is estimated by power spectra. The surface flow in each section is given with a green line, the mid-depth transport with a purple line, and the spectra for total depth-integrated transport is given with the black line. All three subsections, as well as the total, show peaks at the annual and semiannual periods. ENSO-type variability is seen most strongly in the section near Australia. 
lia to South Java, does occur in distinct regions: near the coast of Java, near the coast of Australia, and a section between the two. A simpler, geostrophic-type index, based on the cross-strait pressure difference, would not capture all these processes. To estimate ITF transport from sea level, therefore, locations that capture these dynamics should be included.

\section{ESTIMATE OF ITF TRANSPORT BASED ON SEA LEVEL}

P97 pursued the original work of Wyrtki (1987) and incorporated sea level from four locations into a linear model of geostrophic ITF transport. The four locations were chosen to represent physical processes in the Pacific and Indian Oceans that were thought to control variability in the ITF. The best fit was given as:

$$
\begin{aligned}
\mathrm{V}_{\mathrm{TTF}}^{\mathrm{T}} & =2.40 \eta_{\mathrm{SJ}}-0.91 \eta_{\mathrm{WP}} \\
& -0.23 \eta_{\mathrm{DAR}}-1.41 \eta_{\mathrm{DAV}}
\end{aligned}
$$

where, $\eta_{\mathrm{SJ}}$ is sea level (mean removed, normalized to unit variance) averaged over a region south of Java; $\eta_{\mathrm{WP}}$ is sea level (mean removed, normalized to unit variance) averaged over a region in the western Pacific warm pool; $\eta_{\text {DAR }}$ is sea level (mean removed, normalized to unit variance) at Darwin, Northwest Australia; and $\eta_{D A V}$ is sea level (mean removed, normalized to unit variance) at Davao, Philippines.

The OGCM used to determine the optimal fit of sea level to ITF transport was the Parallel Ocean Climate Model (POCM) of Semtner and Chervin (1992); nine years of monthly mean POCM sea level and velocities were used to derive the fit.

In this new study, results from SODA POP 1.2 are used. To incorporate low-frequency variability from the Indian Ocean, separate from local, Indonesian effects, a fifth station in the equatorial Indian Ocean was included for the new linear model of ITF transport. These five areas correspond to areas of high correlation, in the SODA results, between sea level and ITF transport (Figure 4). The Indian Ocean wave guide along the southern coasts of Sumatra and Java, as well as the Pacific Ocean wave guide along the west coasts of New Guinea and Australia, are evident in the continuous regions of high correlation in the upper layer and total transport, respectively. Total ITF transport, as correlated to sea level (Figure 4 ), is consistent with an "island-rule" (Godfrey, 1989) type of balance, with high correlations evident along the western edge of New Guinea and Australia as well as the equatorial Pacific. Some of these lower-frequency effects are found on higher vertical modes in the ITF, so the new ITF index will use lagged sea level as well as contemporaneous.
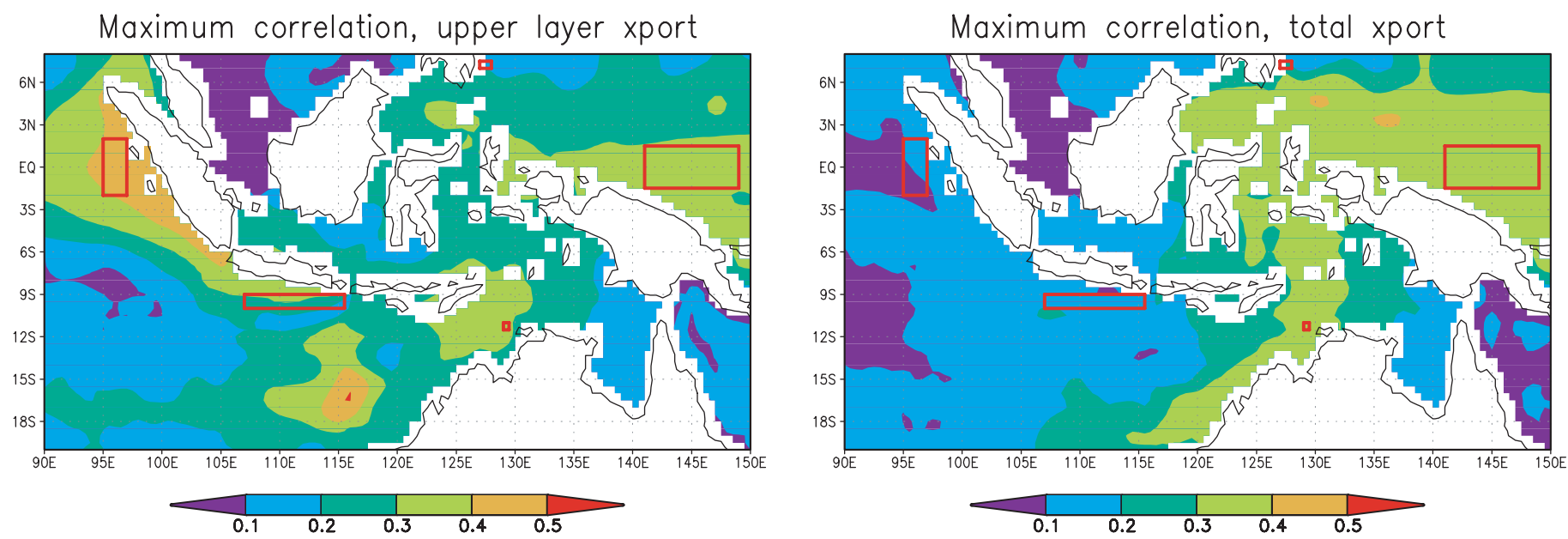

Figure 4. Sea level from the SODA model was correlated to upper layer (left) and total depth-integrated transport (right). Regions that were used to index ITF transport variability are given with the red boxes. These regions have relatively high correlations (sea level to ITF) and also are in regions of dynamical importance: the equatorial Indian Ocean; along South Java; Davao (Philippines); Darwin (Australia); and the western Pacific warm pool. An index of ITF transport was therefore made based on sea level in these discrete locations. 


\section{RESULTS}

\section{Sea Level-ITF Relationship} from SODA

Given the results from the SODA model (specifically the identification of lowerfrequency, first baroclinic mode signals from the Pacific), similar locations were used as in P97, but these were combined with lagged signals at these same sites. The new model for ITF transport is therefore:

$\mathrm{V}_{\text {ITF }}(\mathrm{t})=\Sigma \alpha_{\mathrm{i}} \eta_{\mathrm{i}}(\mathrm{t})+\Sigma \gamma_{\mathrm{i}} \eta_{\mathrm{i}}(\mathrm{t}-\delta \mathrm{t})$,

In this case, the lag $(\delta \mathrm{t})$ was taken to be from one to eight months, roughly the time for Pacific oceanic signals to reach the west coast of Australia (see
England and Huang, 2005). In fact, the wave guide from the Pacific and Indian Oceans are along the coasts, so no significant skill is lost by just using the lagged sea level at Darwin for Pacific interannual variability and at south Java for interannual variability in the Indian Ocean. Using 44 years of monthly mean sea level from SODA, the best skill is obtained when fitting sea level just at South Java and Australia (Darwin) to upper layer ITF transport; including sealevel variations in the equatorial Indian Ocean, western Pacific warm pool, and Davao do not improve the skill. The best fit is thus:

$$
\begin{aligned}
& \mathrm{V}_{\mathrm{ITF}}^{1}(\mathrm{t})=4.96 \eta_{\mathrm{SJ}}(\mathrm{t})-2.16 \eta_{\mathrm{SJ}}(\mathrm{t}-1) \\
& \quad-1.62 \eta_{\mathrm{DAR}}(\mathrm{t}-1)
\end{aligned}
$$

$$
\begin{aligned}
& \mathrm{V}_{{ }^{1}{ }^{\prime}}(\mathrm{t})=2.42 \eta_{\mathrm{SJ}}^{\prime}(\mathrm{t})-1.15 \eta_{\mathrm{SJ}}^{\prime}(\mathrm{t}-1) \\
& \quad-1.16 \eta_{\text {DAR }}^{\prime}(\mathrm{t}-1)
\end{aligned}
$$

The linear model given by [4] reproduces the 0 to $200 \mathrm{~m}$ SODA transport, $\mathrm{V}_{\text {ITF }}^{1}(\mathrm{t})$, with a correlation of 0.85 (Figure 5a).

Note in this case that only sea level from either end of the ITF section is required, but that a component from each at a later month is necessary to get the baroclinic portion of the signal. Much of the skill could be due to the dominance of the annual cycle and coincident variability in sea level. To examine this relationship, a fit was made to the upper layer ITF transport with the mean seasonal cycle removed $\left(\mathrm{V}^{1^{\prime}}{ }_{\text {ITF }}(\mathrm{t})\right.$, equation 5). In this case, the correlation between sea-level fit

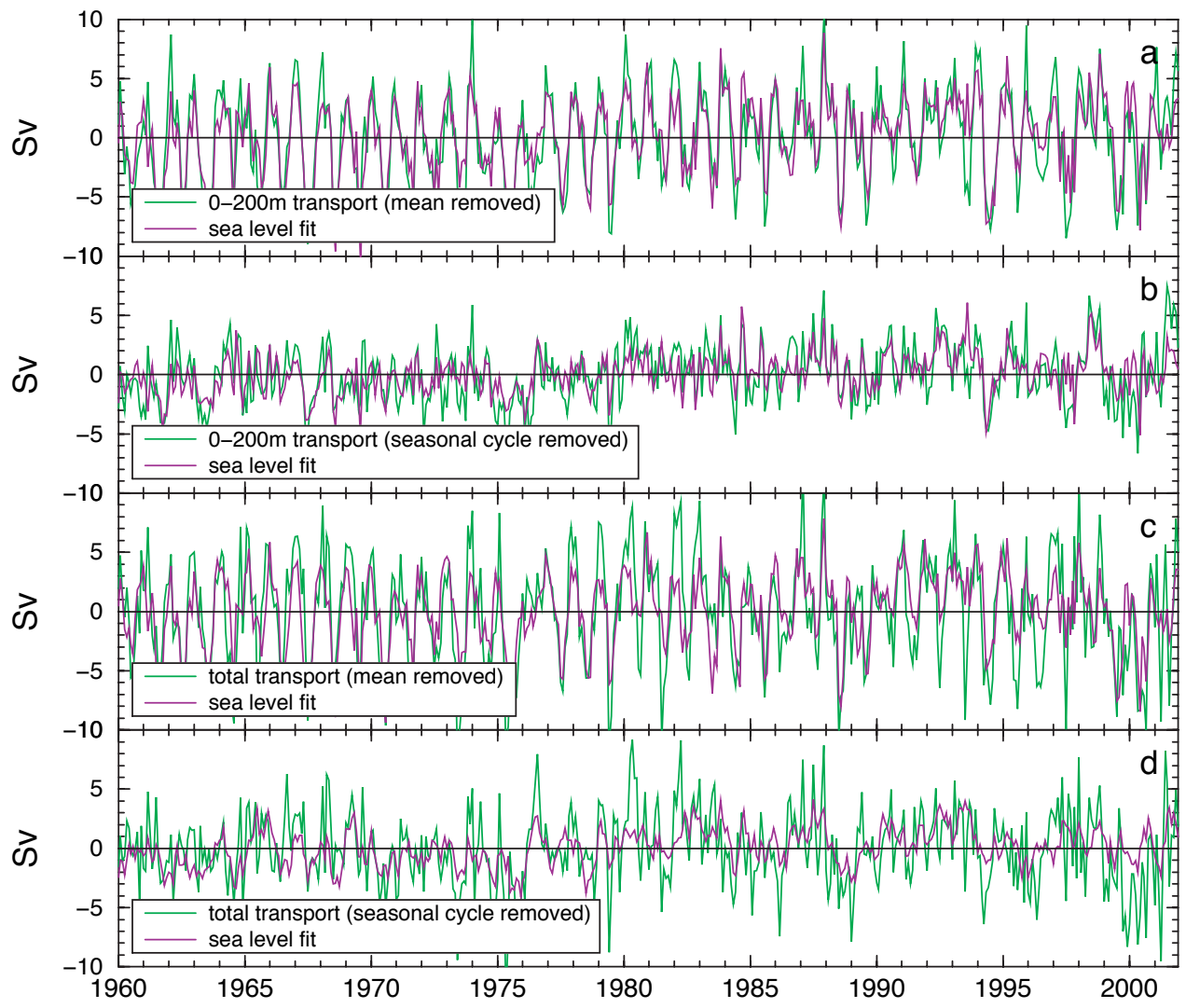

Figure 5. The estimate of ITF transport from sea level at discrete locations (green line) is compared to the actual transport from the SODA model (purple line). Four cases are presented: upper layer transport with and without the mean seasonal cycle (upper two panels) and total transport with and without the mean seasonal cycle (lower two panels). The long-term mean has been removed, and negative numbers indicate an increase in flow from the Pacific to the Indian Ocean. The high correlations in each case indicate the ability of estimating ITF transport from sea level at specific locations. Different fits were determined for each of these cases (see text) because various forcing mechanisms affect transport in the upper layer and at different time scales. 
and model transport is 0.69 (Figure 5b), but the same two locations provide the highest skill in capturing the ITF signal.

The relative sizes, as well as the signs, of the coefficients $\alpha_{i}$ and $\gamma_{I}$ give an indication of the importance of each forcing region. The concurrent sea level at South Java is about twice as important as the other two in both [4] and [5], so at zero lag, the SODA ITF transport is consistent with geostrophic balance; an increase in the along-track pressure gradient (South Java minus Darwin) gives eastward flow, or a reduced ITF transport.

More processes from both the Pacific and Indian Oceans influence the total depth-integrated ITF transport, and the best fit was found using the following:

$$
\begin{aligned}
& \mathrm{V}_{\text {ITF }}^{\mathrm{T}}(\mathrm{t})=3.89 \eta_{\mathrm{SI}}(\mathrm{t})-2.04 \eta_{\mathrm{SJ}}(\mathrm{t}-1) \quad[6] \\
& \quad-1.24 \eta_{\text {DAR }}(\mathrm{t}-1)-1.24 \eta_{\mathrm{DAV}}(\mathrm{t}+1) \\
& \mathrm{V}^{\mathrm{T}}{ }_{\mathrm{ITF}}(\mathrm{t})=1.06 \eta_{\text {EIO }}^{\prime}(\mathrm{t})-1.38 \eta_{\text {DAR }}^{\prime}(\mathrm{t}) \quad[7] \\
& \quad-0.89 \eta_{\mathrm{WP}}^{\prime}(\mathrm{t}-1)+1.06 \eta_{\mathrm{DAR}}(\mathrm{t}-6)
\end{aligned}
$$

In this case, the sea-level fit to transport has lower skill, correlations of 0.70 for the total transport, $\mathrm{V}_{\text {TTF }}^{\mathrm{T}}(\mathrm{t})$, and 0.51 for the seasonal anomalies $\left(\mathrm{V}^{\mathrm{T}^{\prime}}{ }_{\text {ITF }}(\mathrm{t})\right.$; Figure $5 \mathrm{c}$ and d, respectively). Here, variability from the North Pacific (Davao) is required to improve the skill for total transport, while variability from the equatorial Indian Ocean and the western Pacific warm pool are needed to estimate seasonal anomalies of total transport.

\section{ITF Transport Estimate Using} TOPEX/Poseidon

Now that a simple model for ITF transport based on sea level has been determined, the final step is to apply this to the T/P measurements of sea level. One pass of the T/P orbit passes very close to the IX-1 line (see Figure 1). Sea level at a nearly ten-day interval along this pass shows similar variability to the SODA ITF transport. Spectral analysis of sea-level variability (Figure 6) along this line as measured by $\mathrm{T} / \mathrm{P}$ shows a peak in annual energy along the entire section from Australia to south Java. Energy off the coast of Java is dominated by semiannual and interannual variations. Interannual variability in the southern end

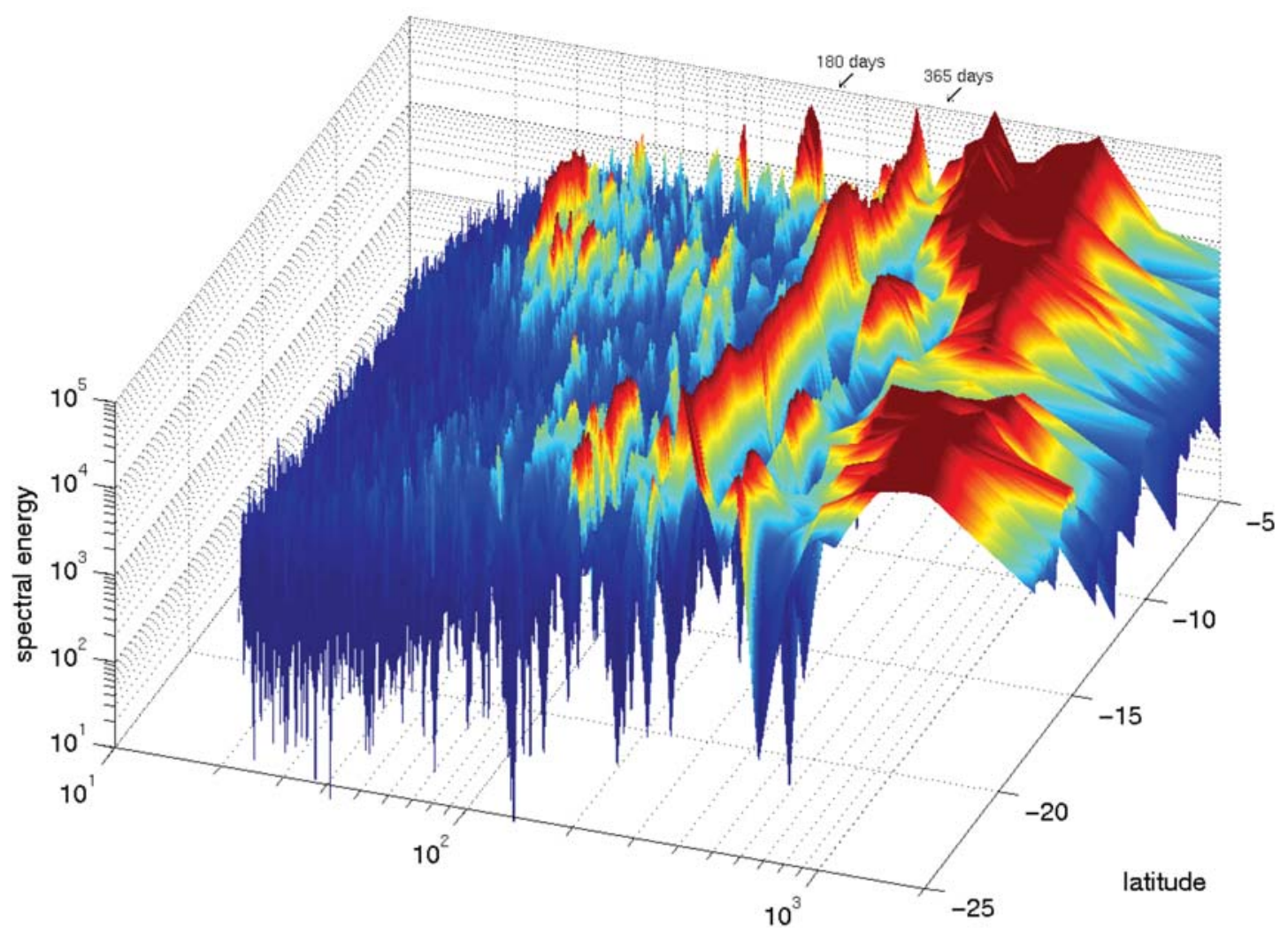

Figure 6. The power spectra from a single along-track pass of the T/P satellite (close to the XBT line in Figure 1) is shown in three dimensions: the period is given along the front axis, location along the track (from Australia to Java) is given along the right axis, and energy is shown vertically. Similar to the SODA results, the T/P has strong semiannual variability all along the section (red ridge at 180 days), strong annual variability near Indonesia, and strong interannual variability near Australia.

period (days) 
of the T/P pass, near Australia, is smaller and occurs at lower frequency than at the northern end of the pass. This is consistent with the SODA results and hypotheses developed previously.

Therefore, the linear model given by equations [4] to [7] was applied to the $\mathrm{T} / \mathrm{P}$ sea level averaged over the same regions given in Figure 4. The results, given in Figure 7, are consistent with the SODA model in terms of variability. The estimate based on T/P, however, shows a smaller seasonal cycle, about a $6 \mathrm{~Sv}$ range. The seasonal anomalies are even smaller, between $+/-2 \mathrm{~Sv}$, and the relationship to ENSO is not obvious. However, it should be cautioned that the fit to total transport anomalies has the weakest skill. There are certainly limitations to the T/P measurements near the coasts where many of the indices are based (although sea level was averaged over a larger region), but the T/P sea level in the regions used in this study have extremely high correlations to the model sea level; correlations are between 0.87 and 0.95 for sea level both with and without the seasonal cycle.

The estimates of transport with seasonal cycle included match the model and observed transport (Figures $7 \mathrm{a}$ and c) better than the anomalies (without a seasonal cycle), despite the high correlation in the input time series. The relatively small differences become more apparent in the transport estimate. For example, in late 1999 through 2002, the model transport anomalies range from -5 to $+8 \mathrm{~Sv}$, while the estimate from T/P are much smaller $(+/-3 \mathrm{~Sv})$. The smaller variations of T/P agree with the transport estimates from Hautala et al. (2001), but it is not clear what is controlling these interannual variations, and why the model might be overestimating them.

\section{CONCLUSIONS}

Sea-level measurements from the TOPEX/Poseidon altimeter have been used to derive an estimate of ITF transport variability. Locations were chosen that highlight specific processes that determine the variations in ITF transport, and a least-square fit was used to determine the relative contributions. The utility of this approach is two-fold: (1) the relative size and sign of the weights give an indication of the important regions, and by extension the forcing, for ITF variations, and (2) such an index may be used

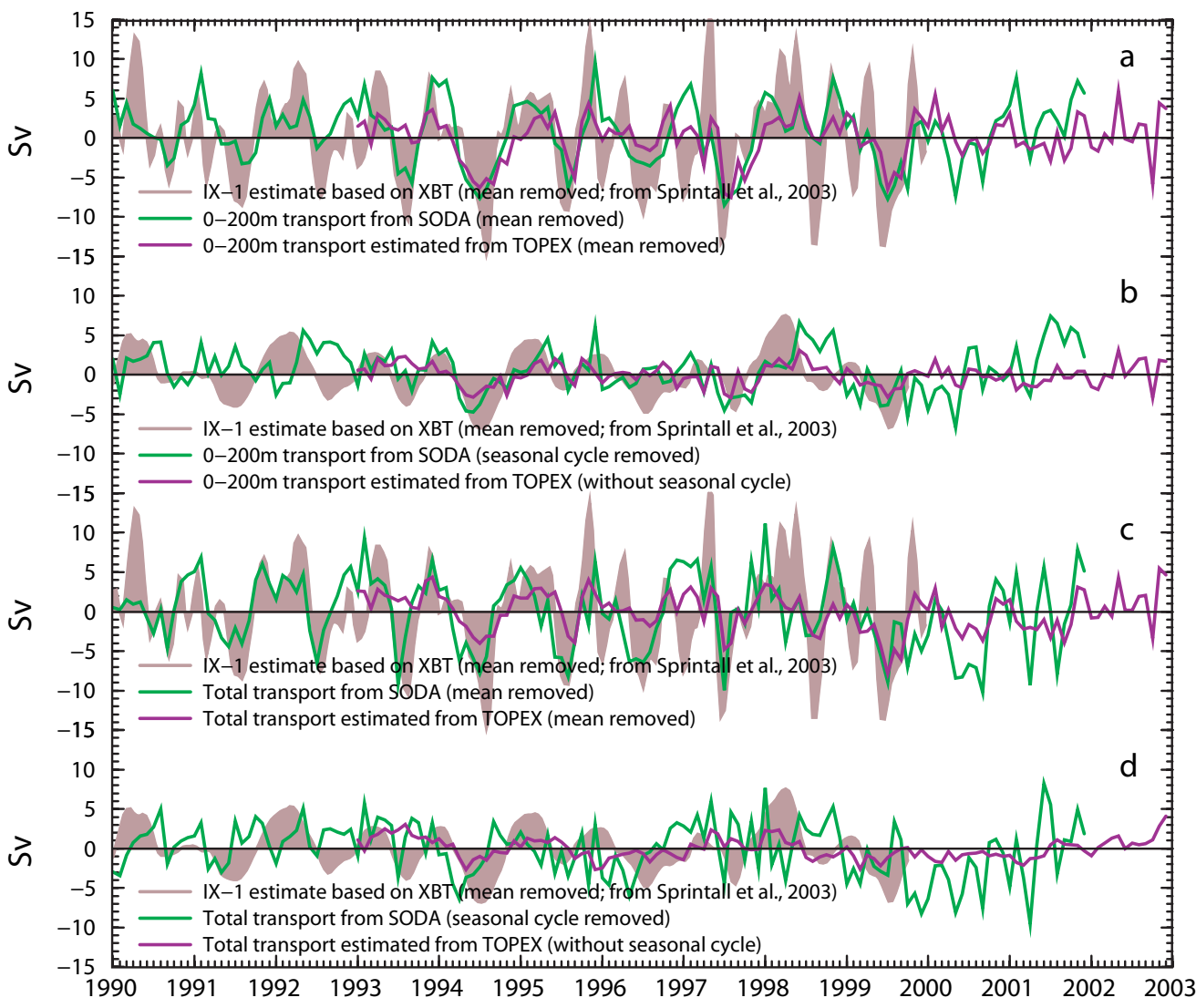

Figure 7. Pacific to Indian Ocean transport was estimated with sea level from the T/P satellite (purple lines). The estimate was constructed based on results from the SODA model (green line). Results from in situ measurements are shown with brown shading. Similar to Figure 5, the upper panels are for transport in the upper $200 \mathrm{~m}$ (with and without the seasonal cycle), and the lower panels are for the total transport. The best estimates are seen for the transport with the seasonal cycle included; seasonal anomalies of transport are not as accurately estimated from sea-level variability. 
to monitor ITF changes with either the global sea-level field from T/P or other satellites or from in situ tide gauges.

By using SODA POP 1.2, the weights of sea level change somewhat from those derived in P97. In that study, timelagged sea level was not considered. This result leads to an index based on the difference between sea level at South Java and a combination of sea level at Darwin, Davao, and the warm pool. The three latter locations all reflect Pacific forcing. In the present study, the introduction of a time lag allows the elimination of the warm-pool location, but again shows an index that is in the geostrophic sense: Indian Ocean sea level (South Java) minus Pacific Ocean sea level (Davao and Darwin).

It is interesting to note that the best fit to total transport is found with sea level at South Java both contemporaneous (indicative of local or near-local forcing) and one month prior (indicative of remotely forced coastal Kelvin waves from the Indian Ocean), as well as at Darwin leading by one month (again indicative of remotely forced coastal Kelvin waves but from the Pacific Ocean), and at Davao. But, the best fit for total transport occurs when sea level at Davao is included with a one-month lag. In other words, processes determining total ITF transport are correlated with sea level at Davao a month later. This correlation could be an Indian Ocean effect, perhaps a result of ITF transport, which then has an effect on Pacific winds, which in turn adjusts sea level at Davao.

Finally, it should be noted that the sea-level locations of Clarke and Liu (1994), and those proposed by Wyrtki (1987) do, in fact, produce a good estimate of upper-ocean ITF transport (equations 4 and 5), but more complex, wider-area forcing is required for total depth ITF transport.

The large-scale nature of ITF forcing, while still being understood, demonstrates the need for suitably large-scale observations for an accurate index. The satellite estimates of sea level provide such a measurement and thus allow for a potential near-real-time monitoring of ITF transport. The net ITF transport, which is forced by several factors in both the Pacific and Indian Oceans at several frequencies, is quite complex, and as new in situ measurements become available, an index such as this can certainly be improved.

\section{ACKNOWLEDGEMENTS}

The author gratefully acknowledges Drs. Roger Lukas and Gary Mitchum for inspiring the initial idea in an earlier paper, and Drs. Susan Hautala and Niklas Schneider for encouraging pursuit of this revised paper. Dr. Ben Giese generously provided the SODA output, and the APDRC at the IPRC serves this to the research community. The diligent work of Dr. Arnold Gordon and three anonymous reviewers is sincerely appreciated. This research was supported by NOAA through grant No. 654477 and by the Japan Agency for Marine-Earth Science and Technology (JAMSTEC) through its sponsorship of the International $\mathrm{Pa}$ cific Research Center. This manuscript is SOEST publication 6672 and IPRC publication 353. 四

\section{REFERENCES}

Carton, J.A., G. Chepurin, X. Cao, and B.S. Giese. 2000. A Simple Ocean Data Assimilation analysis of the global upper ocean 1950-1995, Part 1: Methodology. Journal of Physical Oceanography 30:294-309.

Clark, A., and X. Liu. 1994. Interannual sea level in the northern and eastern Indian Ocean. Journal of Physical Oceanography 24:1,224-1,235.

England, M.H., and F. Huang. 2005. On the interannual variability of the Indonesian throughflow and its linkage with ENSO. Journal of Climate 18:1,435-1,444.

Godfrey, J.S. 1989. A Sverdrup model of the depthintegrated flow for the world ocean allowing for island circulations. Geophysical and Astrophysical Fluid Dynamics 45:89-112.

Gordon, A.L., R.D. Susanto, and A. Ffield. 1999. Throughflow within Makassar Strait transport. Geophysical Research Letters 26:3,325-3,328.

Hautala, S.L., J. Sprintall, J.T. Potemra, A.G. Ilahude, J.C. Chong, W. Pandoe, and N. Bray. 2001. Velocity structure and transport of the Indonesian throughflow in the major straits restricting flow into the Indian Ocean. Journal of Geophysical Research 106:19,527-19,546.

McClean, J.L., D.P. Ivanova, and J. Sprintall. Submitted. Remote Origins of biennial and interannual variability in the Indonesian throughflow region from WOCE IX1 XBT data and a global eddypermitting ocean model. Journal of Geophysical Research.

Meyers, G. 1996. Variation of Indonesian throughflow and ENSO. Journal of Geophysical Research 101:12,255-12,264.

Meyers, G., R.J. Bailey, and A.P. Worby. 1995. Volume transport of Indonesian throughflow. Deep Sea Research Part I 42:1,163-1,174.

Potemra, J.T., S.L. Hautala, and J. Sprintall. 2003. Vertical structure of Indonesian throughflow in a large-scale model. Deep Sea Research II 50:2,1432,162 .

Potemra, J.T., R. Lukas, and G. Mitchum. 1997. Large-scale estimation of transport from the Pacific to the Indian Ocean. Journal of Geophysical Research 102:27,795-27,812.

Saji, N.H. and T. Yamagata. 2003. Possible impacts of Indian Ocean Dipole mode events on global climate. Climate Research 25:151-169.

Saji, N.H., B.N. Goswami, P.N. Vinayachandran, and T. Yamagata. 1999. A dipole mode in the tropical Indian Ocean. Nature 401:360-363.

Semtner, A.J., and R.M. Chervin. 1992. Ocean general circulation from a global eddy-resolving model. Journal of Geophysical Research 97:5,493-5,550.

Sprintall, J., A.L. Gordon, R. Murtugudde, and R. D. Susanto. 2000. A semi-annual Indian Ocean forced Kelvin wave observed in the Indonesian seas in May 1997. Journal of Geophysical Research 105:17,217-17,230.

Wijffels, S., and G. Meyers. 2004. An intersection of oceanic waveguides: Variability in the Indonesian throughflow region. Journal of Physical Oceanography 34:1,232-1,253.

Wyrtki, K. 1987. Indonesian Throughflow and the associated pressure gradient. Journal of Geophysical Research 92:12,941-12,946.

Wyrtki, K. 1961. Physical Oceanography of the Southeast Asian Waters, Naga Report 2, Scripps Institution of Oceanography, 195 pp. 